University of Wollongong

Research Online

Faculty of Engineering - Papers (Archive)

Faculty of Engineering and Information

Sciences

$1-1-2006$

\title{
Effect of particle composition on consolidation of hot briquetted iron
}

Wanda Melfo

wm01@uow.edu.au

Rian J. Dippenaar

University of Wollongong, rian@uow.edu.au

Brian J. Monaghan

University of Wollongong, monaghan@uow.edu.au

Follow this and additional works at: https://ro.uow.edu.au/engpapers

Part of the Engineering Commons

https://ro.uow.edu.au/engpapers/1218

\section{Recommended Citation}

Melfo, Wanda; Dippenaar, Rian J.; and Monaghan, Brian J.: Effect of particle composition on consolidation of hot briquetted iron 2006, 93-100.

https://ro.uow.edu.au/engpapers/1218

Research Online is the open access institutional repository for the University of Wollongong. For further information contact the UOW Library: research-pubs@uow.edu.au 


\title{
Effect of particle composition on consolidation of hot briquetted iron
}

\author{
W. M. Melfo ${ }^{1}$, R. J. Dippenaar*1 and B. J. Monaghan ${ }^{1}$
}

The influence of the carbon concentration of directly reduced iron (DRI) powders on the compressibility and fracture strength of hot briquetted iron ( $\mathrm{HBI})$ has been studied. Industrially produced DRI, pure iron powder and Fe-C alloy powders (synthetic DRI) were used in the study. It was found that the mechanism of compaction could be attributed to pure yielding. The pressure required to attain a given density increased proportionally with the carbon content. The morphology and phases present in DRI powder had a significant influence on the compressibility. The fracture strength of the compacts increased with increasing carbon content of the DRI powder. These observations are discussed with reference to the current understanding of the mechanisms of compaction and fracture of compacted particulate materials.

Keywords: Hot briquelted iron, Direct reduced iron, HBI, DRI, Powder consolidation, Sintering

\section{Introduction}

Hot briquetted iron (HBI), being directly reduced iron (DRI) fines that have been compacted into briquettes, is principally used in the electric arc furnace steelmaking sector as a source of low residual feedstock, but it is also well suited to use as a coolant in the basic oxygen furnace. A major advantage of using HBI instead of finely reduced iron ore is the lessening of transportation problems associated with self-ignition of DRI fines. The HBI that was the subject of the present investigation was produced by the FINMET ${ }^{\circledR}$ process, which involves the reduction of iron ore in a cascade of interconnected fluidised beds with the reduction gas flowing counter current to the solids. ${ }^{1,2}$ The fine iron ores, which are mostly hematite $\left(\mathrm{Fe}_{2} \mathrm{O}_{3}\right)$, are progressively reduced in the solid state at temperatures up to $800^{\circ} \mathrm{C}$ by their passage through a cascade of fluidised bed reactors. The reduced DRI fines are then compacted at a temperature of $\sim 650^{\circ} \mathrm{C}$ between two counter rotating rolls. To prevent fracture and to minimise dust generation during transportation, commercial quality HBI product is required to have a density greater than $5 \times 10^{3} \mathrm{~kg} \mathrm{~m}^{-3}$ and high impact resistance. ${ }^{3}$

The composition of the DRI used for HBI production depends on the extent of reduction of the iron oxide, the extent to which iron particles are carburised and the amount and nature of gangue in the iron ore. The particle size of directly reduced iron produced through the FINMET $^{\circledR}$ process is less than $6.3 \mathrm{~mm}$. The microstructure of these particles consists mainly of pearlite with some proeutectoid cementite precipitated at former austenite grain boundaries and at the surface of the particles. ${ }^{4}$ Remnants of unreduced iron oxides,

${ }^{1}$ Faculty of Engineering, University of Wollongong, NSW 2522, Australia

*Corresponding author, email rian@uow.edu.au mostly wustite or magnetite and occasionally dense hematite, are also present in amounts up to $8 \%$ by mass.

Hot briquetting of fully or partially reduced fine iron ore in the HBI process can be considered analogous to the hot pressing of composite powders. For this reason, the fundamentals of the mechanism and rate of consolidation of powders may be applied, at least as a first approximation, to hot briquetting of iron ores. Specifically, use can be made of hot isostatic pressing (hipping) maps to elucidate the mechanisms of consolidation of iron particles into HBI. ${ }^{5,6}$ Hipping maps have been developed specifically to illustrate in graphical form the relationship between the applied pressure and the relative density of powder compacts at a given temperature. The maps are constructed by using models for each individual mechanism that operates during the isostatic pressing of powder materials at certain temperatures. The pressure applied to a conglomerate of particles is transmitted through the particles as a set of forces acting across their contacts, and elastic deformation occurs initially at these contacts. As the pressure rises and the contact forces increase, the yield strength of the particles is surpassed and plastic deformation occurs. The contact points are transformed into contact areas and, once these contact areas can support the forces without further yielding, time dependent deformation processes determine the rate of further densification. Arzt et $a l^{5}$ considered power law creep as the time dependent mechanism governing densification in the contact zones, and diffusion from grain boundary sources as the mechanism by which pores are filled. Therefore, the maximum density that can be obtained by instantaneous pressing is limited by the yield strength of the particles and corresponds to the boundary line between the yield and creep regions, as illustrated in the hipping diagram shown in Fig. 1. In this graph, values below the yield line are obtained by instantaneous pressing, in which case densification comes about by the 


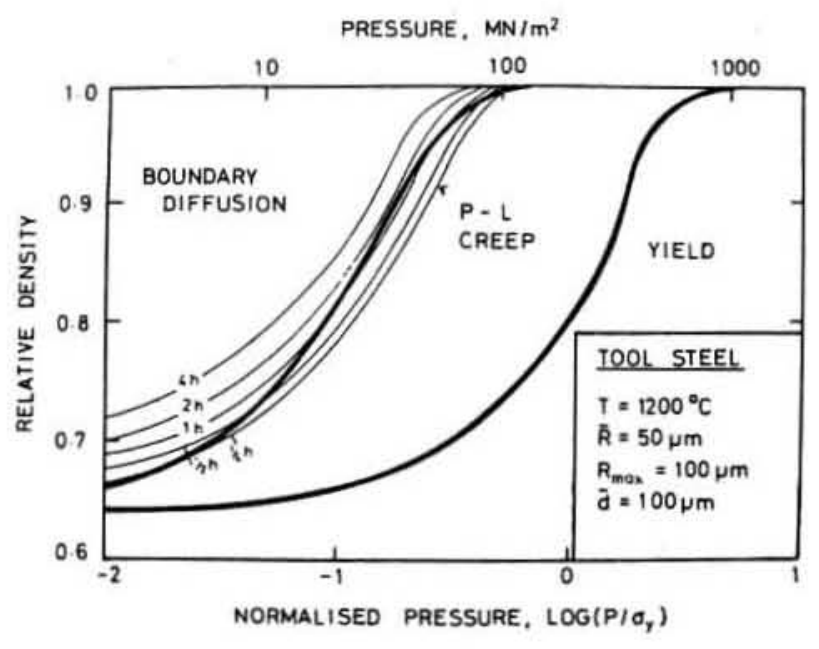

1 Hipping consolidation map for tool steel ${ }^{6}$

plastic flow of individual particles. Densities above the boundary line can only be achieved when time dependent creep and diffusion cause the particles to continue to flow plastically.

Helle et al. ${ }^{6}$ proposed that the limit of densification of a compact by pure yielding is given by the expression

$$
D_{\text {yield }}=\left[\left(1-D_{0}\right) P / 1 \cdot 3 \sigma_{\mathrm{y}}+\left(D_{0}\right)^{3}\right]^{1 / 3}
$$

for relative densities $D$ lower than $0 \cdot 9$, where the particles are partially deformed and the pores are irregularly shaped, as shown in Fig. 2. (Relative density is defined as the ratio between the actual density of the conglomerate of particles and the theoretical full density of the compact.) In equation (1), $D_{\text {yield }}$ is the relative density reached by the arrangement of particulates under instantaneous pressing, $D_{0}$ is the minimum relative density for particles loosely packed, $P$ is the applied pressure and $\sigma_{\mathrm{y}}$ is the yield strength of the particles.

At relative densities above $0 \cdot 9$, the particles are no longer spherical, and the shape of individual particles resembles more closely a polyhedron. This assumption implies that particles are no longer in point contact but that contact areas are a more realistic description of the interparticle connections. This means that when a force is applied to the compact, yielding of individual particles will not occur, and the applied force will be transferred from one particle to the other so that the compact approaches bulk deformation behaviour. In this instance, further plastic deformation is calculated by the yield of a thin spherical shell surrounding each pore, as in Fig. 2. In such a case, the density attained by compaction $(D>0 \cdot 9)$ is expressed as

$$
D_{\text {yield }}=1-\exp \left(-3 P / 2 \sigma_{\mathrm{y}}\right)
$$

Although hipping diagrams are extremely useful and can be employed to discriminate between the different mechanisms of compaction, their use is limited to the density changes occurring during hipping. However, the use of these diagrams can be extended to model uniaxial pressing by taking into consideration the influence of wall friction and uneven pressure upon the final density of the compact. While these broadened models can be usefully employed, it should be noted that their use is limited to the analysis of single phase, spherical particles of a uniform composition and size. Unfortunately, the

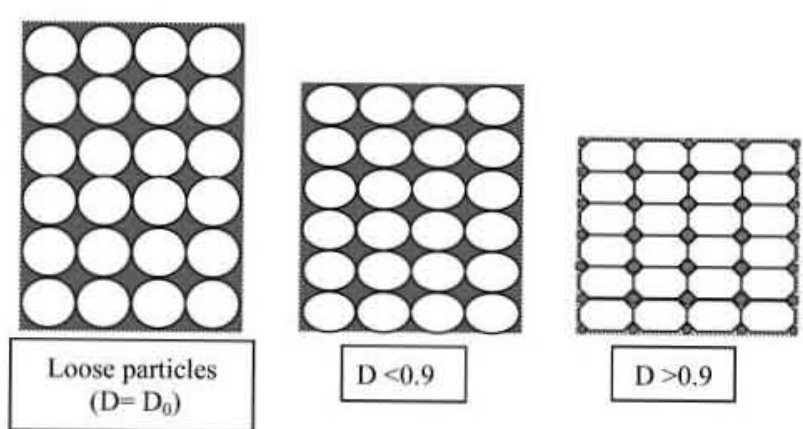

2 Representation of particles and pores during compaction based on principles used by Helle et al. ${ }^{6}$ to determine yield density: $D$ relative density, $D_{0}$ minimum relative density for particles loosely packed

DRI fines that are used to produce HBI are far more complex, as they vary in composition, phase distribution and morphology and hence have variable compaction behaviour. It is therefore essential to determine to what extent the underpinning theory on which HBI diagrams are based can be applied to analysis of the compaction behaviour of more complex particles.

Turner and Ashby, ${ }^{7}$ addressing the consolidation of a combination of particles with different hardness, confirmed that, depending on the number of hard particles present in the mixture, two mechanisms can govern densification: either the hard particles form a rigid network that supports a substantial portion of the applied stress of compaction, or the presence of hard particulates compels the softer particles to deform more severely in order to reach the same density. Furthermore, Hewitt et al. ${ }^{8}$ found that irregularly shaped particles consolidate more readily than spherical particles, and attributed the improved compaction behaviour to the fact that irregularly shaped particles promote asymmetrical loading, creating shear stresses and interparticle sliding and, consequently, frictional welding of freshly exposed surfaces. Therefore, irregular particles have higher compressibility than that of spherical particles. ${ }^{8}$

The consolidation of DRI fines in the HBI process has only been examined in a few instances..$^{9-13}$ These studies have shown that the source of iron ore and, hence, the exact nature and morphology of the individual particles, as well as the carbon content of the DRI particles, affect the compressibility of iron fines used in the HBI process. However, a satisfactory account of the mechanisms responsible for the consolidation of HBI has not been given as yet.

In an attempt to resolve some of the uncertainties and unknowns of the consolidation of partially or fully reduced iron ores, the present work studied the influence of the carbon content of DRI powders on compressibility. Furthermore, the fracture strength of hot briquetted iron was determined, and, for the sake of comparison, synthetically prepared iron powders were studied in addition to industrially prepared DRI powders.

\section{Experimental}

The DRI fines were compacted under controlled laboratory conditions in an attempt to simulate the HBI process. Experimental trials were conducted to 
assess the compressibility of DRI powders produced industrially and in the laboratory, and the resistance to fracture of the compacted products. Details of the materials and testing techniques are outlined below.

\section{Materials}

Industrially produced DRIs, the compositions of which are given in Table 1, were used to determine whether there is a difference in compacting behaviour between materials from two different plants (A and B) and in each plant from different iron ore sources.

'Synthetic DRI' (with pure iron powder as the starting material) was prepared in the laboratory to investigate the effect of different degrees of carburisation of iron particles on their compacting behaviour. The carbon content (Table 2) of these iron particles, which henceforth are referred to as synthetic iron powders, was calculated from metallographic image analysis. Figure 3 indicates the compositions on the $\mathrm{Fe}-\mathrm{C}$ diagram of the synthetic DRI powders used in the present study.

\section{Carburisation}

To prepare the synthetic materials, pure atomised Höganäs AHC 100.29 iron powder with particle sizes of less than $1.5 \times 10^{-4} \mathrm{~m}$ was carburised. The carburisation of iron powder was carried out by pack carburising as follows: $0.02 \mathrm{~kg}$ of iron particles was mixed with $0 \cdot 1 \mathrm{~kg}$ of charcoal, of less than $2 \times 10^{-3} \mathrm{~m} \mathrm{dia}$. in size, and $10 \%$ by mass of anhydrous sodium carbonate $\left(\mathrm{Na}_{2} \mathrm{CO}_{3}\right)$; the mixture was then placed in a crucible and heated to the predetermined temperature, time and cooling rates specified in Table 3 and the carburised iron powder extracted using magnetic separation followed by rinsing in acetone.

\section{Experimental techniques Compressibility}

The industrial as well as the synthetic DRI fines were compacted in a high temperature mould. All compaction experiments were conducted in an Instron 1343 hot

Table 1 Composition of directly reduced iron (DRI) produced in FINMET ${ }^{\circledR}$ process

\begin{tabular}{llllll}
\hline \multicolumn{5}{c}{ Composition, wt-\% } \\
\cline { 2 - 6 } DRI source & Fe total* $^{*}$ & Fe met. & C & $\mathrm{SiO}_{2}$ & $\mathrm{Al}_{2} \mathrm{O}_{3}$ \\
\hline A1 & $\mathrm{NA}$ & 84.4 & 0.90 & 2.5 & 0.90 \\
A2 & 91.8 & 83.0 & 0.94 & 2.8 & 0.89 \\
A3 & 92.6 & 85.1 & 1.2 & 2.3 & 0.91 \\
A4 & 91.8 & 82.5 & 1.6 & 2.1 & 0.84 \\
B1 & 93.2 & 83.1 & 0.71 & 0.94 & 1.1 \\
B2 & 92.8 & 84.3 & 1.9 & 0.95 & 0.80 \\
\hline
\end{tabular}

*NA denotes not available.

${ }^{\dagger}$ met. denotes metallic.

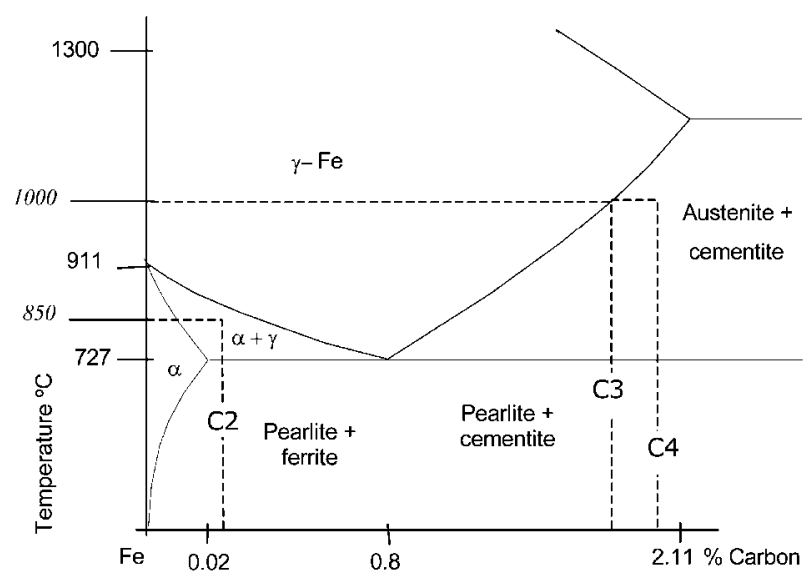

3 Iron-carbon phase diagram showing compositions of synthetic directly reduced iron (DRI) products C2-C4 (axes not to scale)

compression testing facility, equipped with a $5 \times 10^{4} \mathrm{~N}$ load cell. An infrared furnace was used to heat the compaction system in air to the specified temperature. The samples obtained using this mould were cylindrical in shape, having a diameter of $1.03 \times 10^{-2} \mathrm{~m}$ and height ranging from $2 \times 10^{-3}$ to $5 \times 10^{-3} \mathrm{~m}$. A schematic illustration of the compacting process is shown in Fig. 4.

The compacts were heated at a rate of $8 \cdot 3 \mathrm{~K} \mathrm{~s}^{-1}$ to the compacting temperature of $650^{\circ} \mathrm{C}$. A predetermined compacting pressure was applied following a $300 \mathrm{~s}$ soaking time. The speed of compaction was $4 \times 10^{-4} \mathrm{~m} \mathrm{~s}^{-1}$ in all instances. For the industrially produced DRI fines, only particles of less than $1 \times 10^{-3} \mathrm{~m}$ were used.

The density of the compacted samples was determined according to ASTM standard B331 by measuring dimensions and mass. ${ }^{14}$ An average of 12 samples were compacted for each type of DRI fines. To ensure repeatability, at least three compacts were produced at each applied pressure.

\section{Fracture resistance}

The resistance to fracture of the compacts was determined by a diametrical compression test (DCT) ${ }^{15,16}$ schematically shown in Fig. 5. A mechanical testing machine, Instron 4302, with a load cell of $1 \times 10^{-4} \mathrm{~N}$ was used for the test. Samples were placed between two brass pads to assist in correct distribution

Table 2 Carbon content (calculated) of synthetic DRI products

\begin{tabular}{ll}
\hline Material & Carbon content, wt-\% \\
\hline C2 & 0.31 \\
C3 & $1 \cdot 63$ \\
C4 & $1 \cdot 77$ \\
\hline
\end{tabular}

Table 3 Carburisation conditions used in production of synthetic DRI powders

\begin{tabular}{|c|c|c|c|c|c|c|}
\hline \multirow[b]{2}{*}{ Material } & \multicolumn{3}{|l|}{ First carburisation } & \multicolumn{3}{|c|}{ Second carburisation } \\
\hline & Temperature, ${ }^{\circ} \mathbf{C}$ & Time, $\min$ & Cooling rate, $\mathrm{K} \mathrm{h}^{-1}$ & Temperature, ${ }^{\circ} \mathrm{C}$ & Time, $\min$ & Cooling rate, $\mathrm{K} \mathrm{h}^{-1}$ \\
\hline $\mathrm{C} 2$ & 850 & 5 & In furnace $\sim 40$ & $\ldots$ & $\ldots$ & $\ldots$ \\
\hline C3 & 1000 & 5 & In furnace $\sim 40$ & $\ldots$ & $\ldots$ & $\ldots$ \\
\hline C4 & 1000 & 20 & 500 & 1000 & 5 & In furnace $\sim 40$ \\
\hline
\end{tabular}




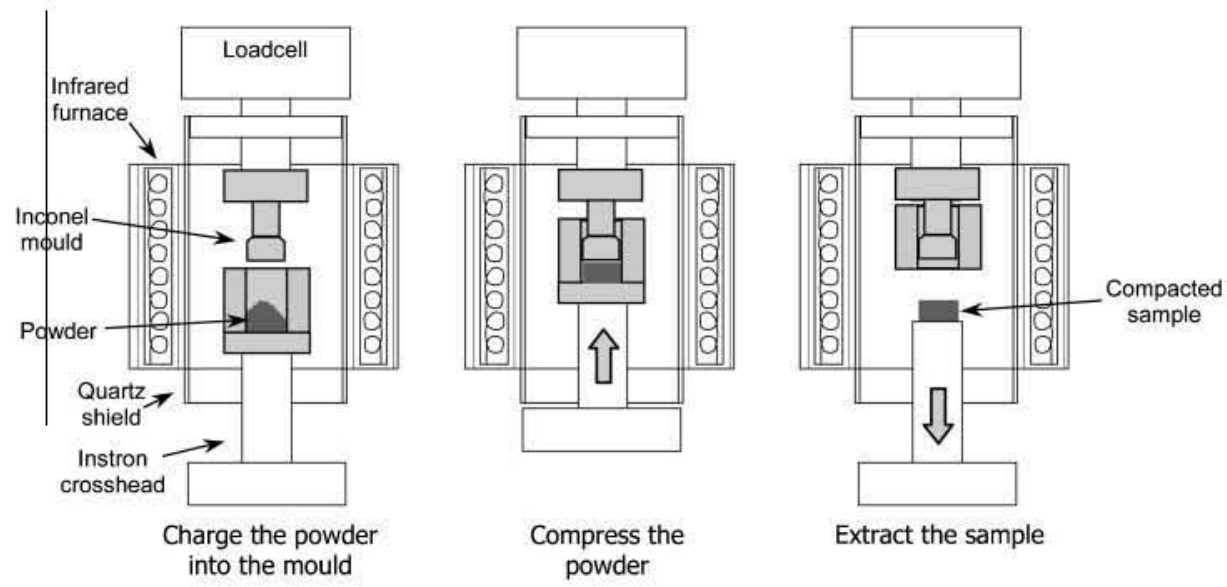

4 Schematic illustration of compression process for production of compacted samples

of the load. Not all of the compacted samples fractured in a brittle fashion as required for a valid DCT, but, under such circumstances, the force applied to produce fracture was assumed to be a normalised force $F_{\mathrm{n}}$ independent of the sample thickness.

\section{Results}

\section{Compressibility}

Industrial DRI

The experimentally determined compressibilities of FINMET ${ }^{\circledR}$ DRI fines from the two different industrial plants are shown in Fig. $6 a$. The horizontal dashed line represents the HBI process target density of $5 \times 10^{3} \mathrm{~kg} \mathrm{~m}^{-3}$, and compacts with densities below this value are not considered a desirable product. ${ }^{3}$ The density of the compacts increases logarithmically with an increase in applied pressure. The results depicted in Fig. $6 a$ are represented on a more sensitive scale in Fig. $6 b$, and it follows that sample B1 has the highest compressibility, requiring an applied pressure of only $150 \mathrm{MPa}$ to achieve the target density. Sample A4 has the lowest compressibility, requiring an applied pressure in excess of $240 \mathrm{MPa}$ to attain the target density. Densities obtained at a constant applied pressure of $190 \mathrm{MPa}$ and at a compacting temperature of $650^{\circ} \mathrm{C}$ are shown in Fig. 7 as a function of the carbon content of each sample.

It follows from Fig. 7 that an increase in the carbon content of compacted powders lowers the compressibility. The DRI from plant A displays a different

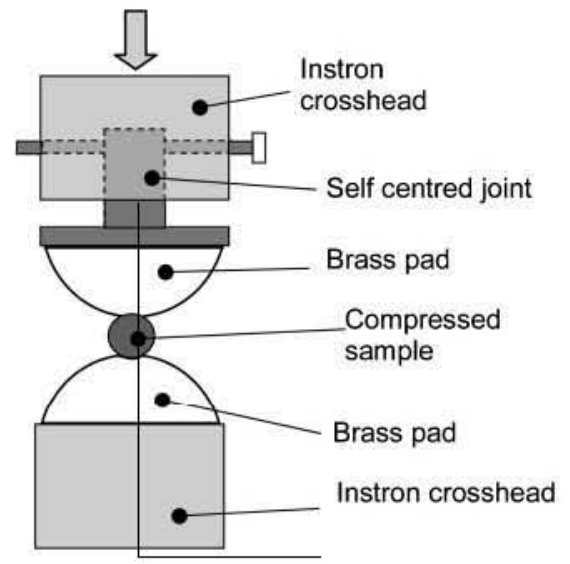

5 Schematic illustration of diametrical compression test

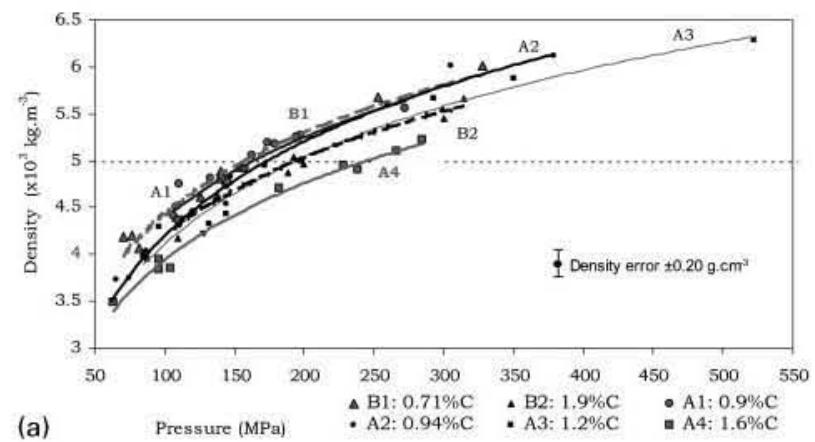

(a)

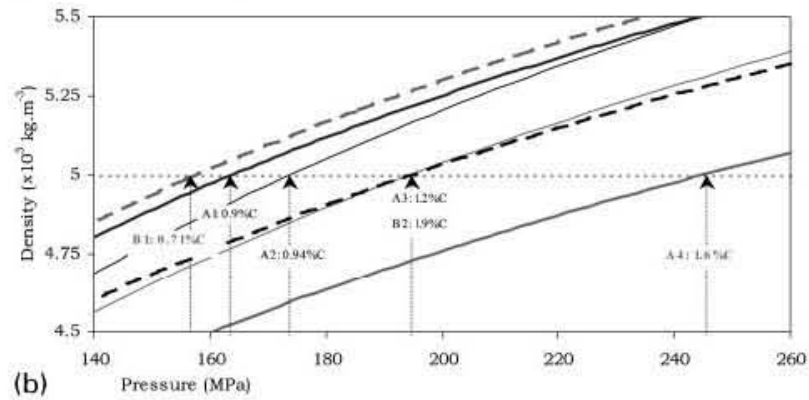

a compressibility curves (Refs. 12 and 13); $b$ highlighting required pressures to attain target density for different DRI sources at compacting temperature of $650^{\circ} \mathrm{C}$

6 Compressibility curves for industrial DRI powders compressed at $650^{\circ} \mathrm{C}$

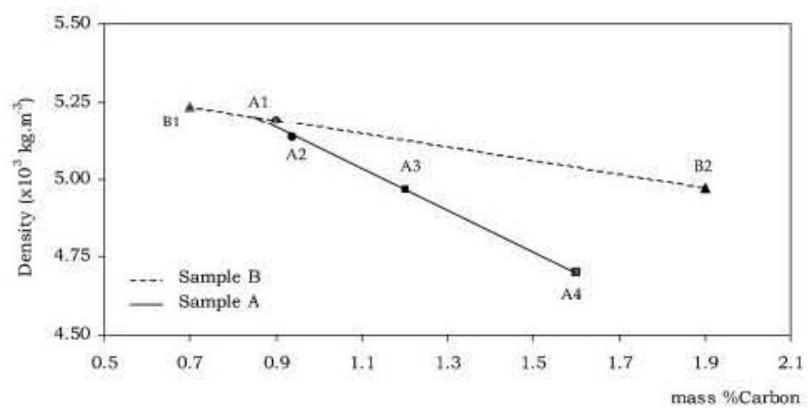

7 Relationship between density and carbon content of DRI samples compacted at $190 \mathrm{MPa}$ and $650^{\circ} \mathrm{C}$ (Refs. 12 and 13) 


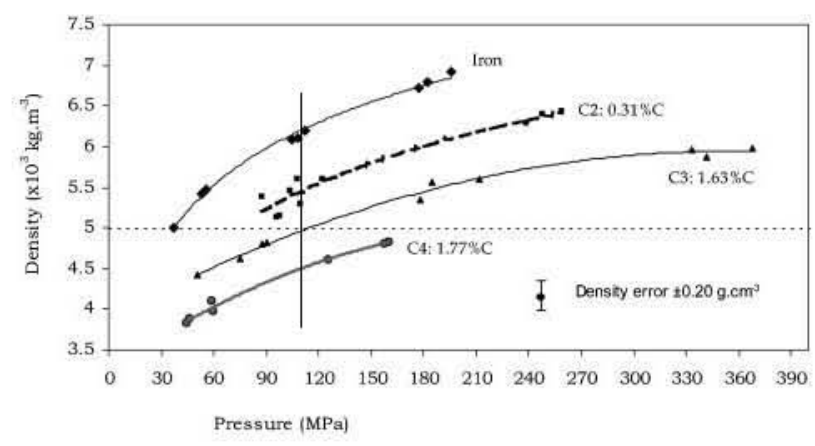

8 Compressibility curves for synthetic powders (iron and iron-carbon alloy powders) compressed at $650^{\circ} \mathrm{C}$ (Ref. 13)

carbon-density relationship than that of the DRI produced in plant B. Samples from plant B have higher compressibility than that of the material from plant A, irrespective of the carbon content.

\section{Synthetic DRI}

In an attempt to clarify further the influence of carbon content on DRI compressibility, powders prepared in the laboratory were compressed experimentally under the same experimental conditions as for the industrial DRI fines. The compressibility curves of these samples are depicted in Fig. 8. Pure iron has the highest compressibility, followed by hypoeutectoid steel C2 $(0 \cdot 31 \% \mathrm{C})$, hypereutectoid steel C3 $(1 \cdot 63 \% \mathrm{C})$ and finally C4 $(1 \cdot 77 \% \mathrm{C})$, which shows the lowest compressibility. Pressures lower than $40 \mathrm{MPa}$ are sufficient to achieve the required density of $5 \times 10^{3} \mathrm{~kg} \mathrm{~m}^{-3}$ in atomised pure iron powder, but a pressure of up to $180 \mathrm{MPa}$ is required to achieve the same density with heavily carburised particles such as $\mathrm{C} 4$.

\section{Fracture resistance}

\section{Compacted industrial DRI}

The relationship between the fracture force $F_{\mathrm{n}}$ and the density of compacts produced from industrial DRI is shown in Fig. $9 a$. The force required to fracture a compacted sample increases non-linearly with increasing density of the sample. There is an ill defined dependence of the fracture force on the DRI particle source or composition below a density of $\sim 5 \times 10^{3} \mathrm{~kg} \mathrm{~m}^{-3}$. All samples below this density have, within experimental uncertainty, the same fracture-density profile. At densities above $5 \times 10^{3} \mathrm{~kg} \mathrm{~m}^{-3}$ the compressibility curves begin to diverge.

On a more expanded scale around the target density of $5 \times 10^{3} \mathrm{~kg} \mathrm{~m}^{-3}$, shown in Fig. $9 b$, it appears that the fracture resistance of compacted DRI samples with densities higher than $5 \times 10^{3} \mathrm{~kg} \mathrm{~m}^{-3}$ can be presented in the following decreasing order of strength: A4 $(1 \cdot 6 \% \mathrm{C})$, B2 $(1 \cdot 9 \% \mathrm{C}), \mathrm{B} 1(0 \cdot 71 \% \mathrm{C}), \mathrm{A} 3(1 \cdot 2 \% \mathrm{C}), \mathrm{A} 2(0 \cdot 94 \% \mathrm{C})$ and $\mathrm{A} 1(0 \cdot 90 \% \mathrm{C})$.

The fracture forces of samples with densities of $5 \times 10^{3}$ and $5.5 \times 10^{3} \mathrm{~kg} \mathrm{~m}^{-3}$, respectively, are displayed in Fig. 10. It follows that an increase in carbon content increases the fracture resistance of the compacts, providing that the density is high enough. Figure 10 also shows that the fracture resistance of compacted DRI manufactured in plant $A$ is more sensitive to the carbon content of the particles than those manufactured in plant B.
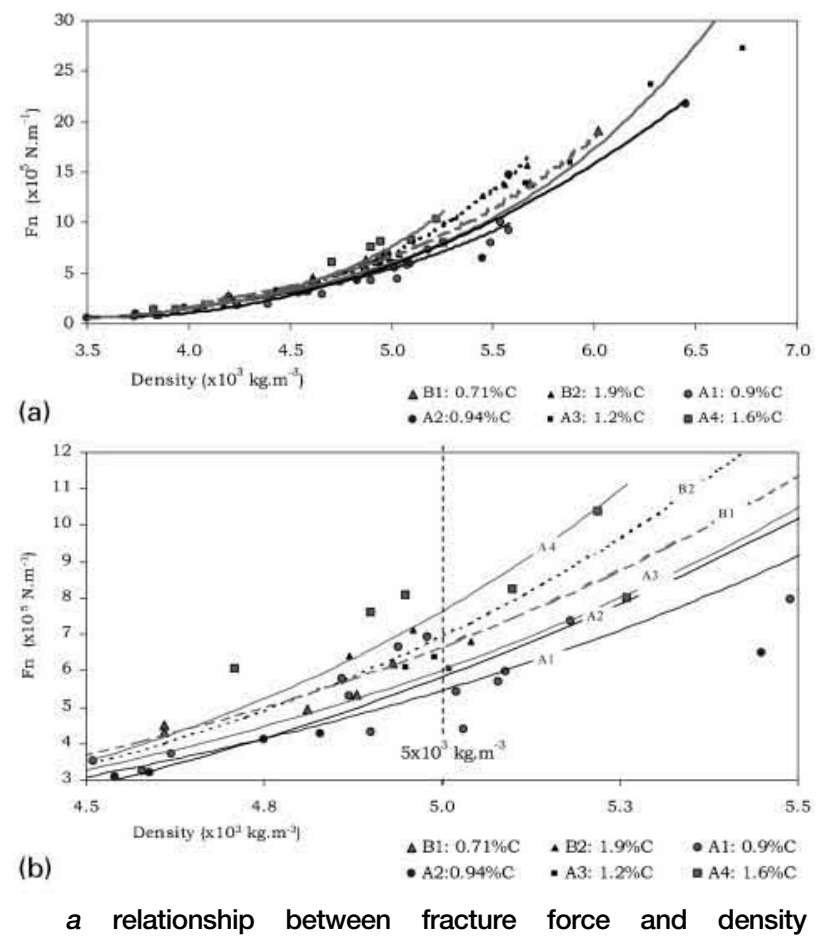

a relationship between fracture force and density target density

9 Relationship between fracture force $F_{n}$ and density in DRI samples compacted at $650^{\circ} \mathrm{C}$

\section{Compacted synthetic DRI}

The fracture forces for compacts produced from synthetic DRI are shown in Fig. 11a. Closer scrutiny of the curves (Fig. 11b) reveals that there is a greater dependence of the fracture force on density in the high carbon samples, C4 $(1.77 \% \mathrm{C})$ and $\mathrm{C} 3(1.63 \% \mathrm{C})$, than in the low carbon, $\mathrm{C} 2(0 \cdot 31 \% \mathrm{C})$, and pure iron samples. If the curves are extrapolated beyond a density of $6 \times 10^{3} \mathrm{~kg} \mathrm{~m}^{-3}$, the fracture resistance increases with an increase in the carbon content in the same fashion as for the industrial DRI samples. However, samples of high carbon alloys could not be produced to densities higher than $6 \times 10^{3} \mathrm{~kg} \mathrm{~m}^{-3}$, and samples of iron or low carbon steel could not be produced with densities lower than $5 \times 10^{3} \mathrm{~kg} \mathrm{~m}^{-3}$, so this correlation is somewhat speculative.

A comparison of Figs. 9 and 11 reveals that synthetic samples with the same density (for example $5 \cdot 25 \times 10^{3} \mathrm{~kg} \mathrm{~m}^{-3}$ ) had a fracture resistance between $1 \times 10^{5}$ and $5 \times 10^{5} \mathrm{~N} \mathrm{~m}^{-1}$, while the fracture resistance

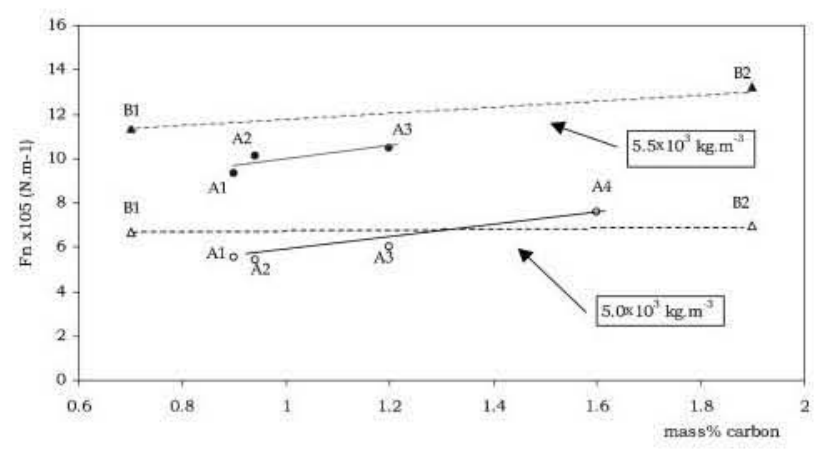

10 Influence of carbon content on fracture strength of DRI compacted samples at two different densities: compacting temperature $650^{\circ} \mathrm{C}$ (Refs. 12 and 13) 

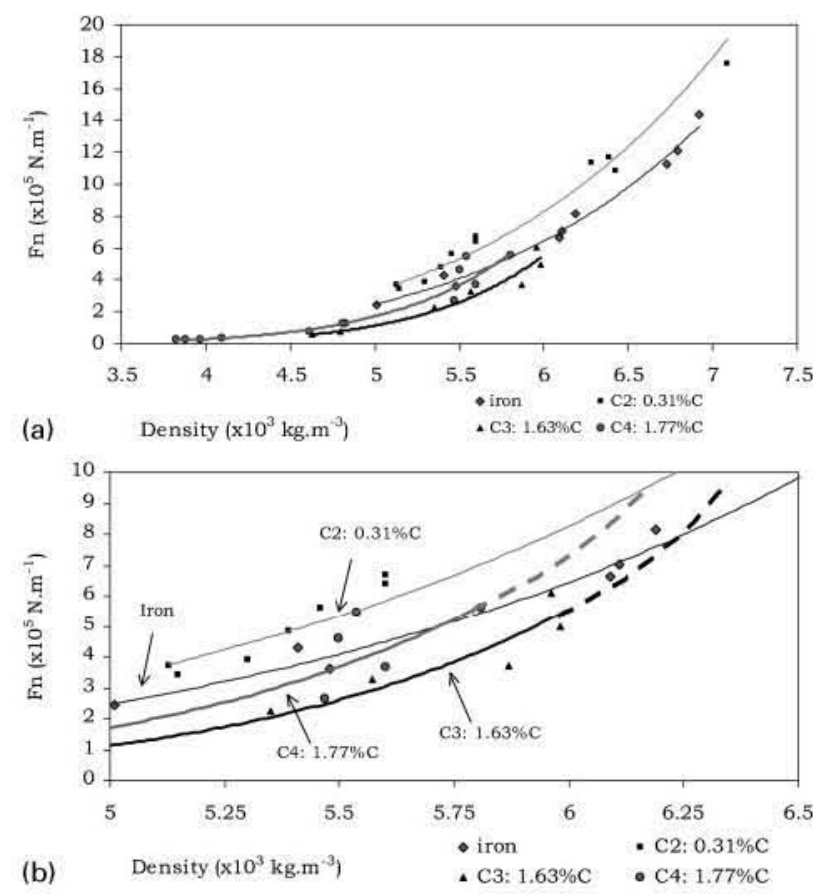

a relationship between fracture force and density (Ref. 13): samples of density values higher than those reported in Fig. 8 are included although compacting pressure is unknown; $b$ highlighting breaking forces at target density

11 Relationship between fracture force and density for synthetic material compacted at $650^{\circ} \mathrm{C}$

of industrial DRI compacts was in excess of $6 \times 10^{5} \mathrm{~N} \mathrm{~m}^{-1}$. Hence, samples of industrially produced DRI are much more resistant to fracture than samples produced from synthetic particles.

\section{Discussion}

An important finding of the present study is that the compressibility of iron particles is adversely affected by an increase in the carbon content of such particles. On the other hand, an increase in carbon content of the iron particles in the compact results in a significant increase in their fracture resistance. Another finding of industrial importance is that iron particles derived from different iron ore bodies respond very differently with respect to compressibility. The origin, nature and mineralogy of the ore body also seem to influence markedly the fracture resistance of the compacts.

In an attempt to establish the mechanism by which synthetic DRI compacts are consolidated, the experimental compaction data were analysed by the use of hipping maps. An unpacked density $D_{0}$ of 0.48 was determined for the synthetic powders and utilised in construction of the maps. The expressions of Helle et al. ${ }^{6}$ (equations (1) and (2)) were used to construct three yield curves. The reference curve was constructed for pure iron, assuming a yield strength of $5 \mathrm{MPa}$ (with the aid of the deformation mechanism map of pure iron, ${ }^{17}$ it was determined that polycrystalline pure iron with $100 \mu \mathrm{m}$ grain size tested at $650^{\circ} \mathrm{C}$ will have a yield strength of $5 \mathrm{MPa})$. A second curve was constructed for particles with a yield strength of $200 \mathrm{MPa}$ and a third for particles with yield strength $500 \mathrm{MPa}$. These curves are shown in Fig. 12 together with the experimentally determined compressibility curves for 'pure iron' particles, for the three groups of carburised iron particles and for industrial DRI. It is pertinent to emphasise that the Arzt et al $^{5}$ model predicts that when pure plastic flow accounts for the densification of particles, the intercept between the applied pressure and the density attained will fall within the yield region of the diagram. Only a time dependent process following compaction can account for densities attained in the creep region.

Figure 12 shows that the experimentally determined values for compacts formed from pure iron powder, industrially produced DRI and carburised iron synthetic compacts lie below the yield curve for pure iron compaction, i.e. totally within the yield region of the diagram. By comparing the predicted flow curve of iron based on an estimated yield strength of $5 \mathrm{MPa}$ (Ref. 16) with the experimentally determined compressibility curve for 'pure iron', it follows that the iron particles used in the present experiments have a yield strength in excess of $5 \mathrm{MPa}$. It is also evident that the compacts formed from carburised iron powders all have higher yield strengths than those of compacts formed from pure iron powder. For example, C2 particles with $0.31 \% \mathrm{C}$ lie approximately on the $200 \mathrm{MPa}$ yield curve, and, by

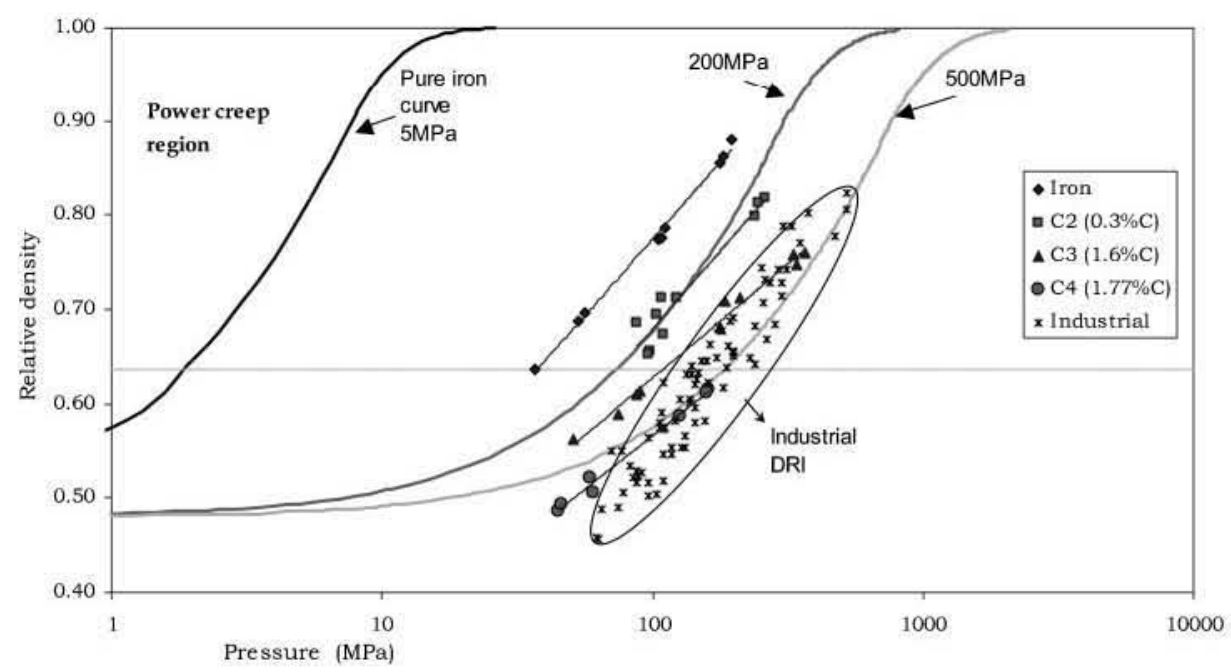

12 Predicted hipping maps for pure iron particles, particles with yield strengths of $200 \mathrm{MPa}$ and $500 \mathrm{MPa}$, respectively, compacted at $650^{\circ} \mathrm{C}$ and experimentally determined compressibility curves for pure iron and carburised samples 
inference, the industrially produced DRI has yield strengths $\sim 500 \mathrm{MPa}$.

It is pertinent to inquire into the relevance of applying hipping mapping to the present study. First, the compacts in the study were produced by uniaxial compression and not by hipping. Second, the underpinning theoretical basis for the hipping mapping technique has been developed for single phase, homogeneous materials only, and not for the multiphase DRI used in the production of HBI. However, the fact that the slope of the experimentally determined compressibility lines resembles closely the slope of the theoretical curves from the hipping maps corresponding to similar yield strengths provides some confidence that the technique of hipping mapping may be applied to the uniaxially compressed compacts produced in the present study. Moreover, the family of compressibility curves determined for compacts made from industrially produced DRI falls within a narrow band bordered by those of synthetic compacts of different carbon contents. These observations provide at least some justification that hipping mapping diagrams may be applied to analysis of the compaction of industrially produced DRI. Therefore, should it be justified to apply the hipping mapping approach to the compressibility of DRI powders and should the compaction test be a satisfactory simulation of the hot briquetting process, then it would be reasonable to conclude that compaction of particles in the hot briquetting process occurs by a pure yielding mechanism and that creep does not play a role in the compaction process.

Turner and Ashby ${ }^{7}$ proposed that when a mixture of particles of different hardness is compressed, the softer, more ductile particles will deform under pressure, but that the extent of deformation will be impeded by the presence of the harder material. These principles may now be applied to the synthetic DRI samples studied in the present investigation. In the pure iron compact, the soft ferrite yields easily, and a compact of high density is produced. In the compact containing $0.31 \% \mathrm{C}$, the microstructure consists of $63 \%$ primary ferrite, formed on austenite grain boundaries, and $27 \%$ pearlite. The pearlite colonies, consisting of ferrite lamellae finely interspersed with cementite lamellae, are much harder than ferrite, and the deformation will be concentrated in the soft ferrite matrix. Less yielding will occur and the density of the compact is expected to be lower than that of the pure iron compact. This expectation is borne out by experiment. It should be noted, though, that even if the ferrite contained in the pearlite structure is of the same composition as primary ferrite, deformation of the ferrite lamellae is severely restricted by the presence of cementite lamellae in the pearlite. Hence, the work hardening rate of the pearlitic ferrite would be much higher and the pearlite colony may essentially be viewed as a zone of greater hardness.

In the compacts of synthetic powder containing 1.63 and $1.77 \% \mathrm{C}$, respectively, the microstructural development is quite different. Hard, primary cementite is present on former austenite grain boundaries and the rest of the microstructure consists of pearlite. On compaction, deformation will concentrate in the softer ferrite, but, because the interlamellar spacing is only a fraction of a micrometre, the ferrite will work harden much more, and the presence of the hard, finely

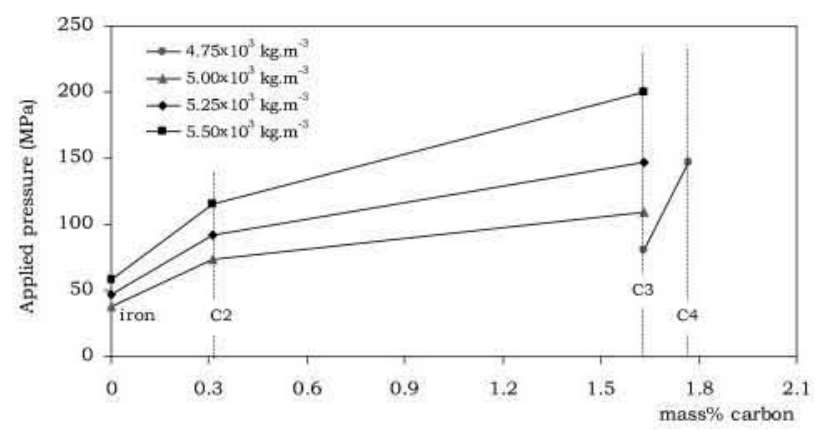

13 Relationship between compacting pressure, carbon content and density for carburised samples compressed at $650^{\circ} \mathrm{C}$

dispersed cementite particles will restrict further deformation of the ferrite and, hence, compacts of lower density will be produced. Because the compact containing $1.77 \% \mathrm{C}$ will have even more cementite $(26 \cdot 3 \%)$ than the compact containing $1.63 \% \mathrm{C}(24 \cdot 2 \%)$, the deformation of ferrite in this compact will be even more restricted by the network of cementite (a mechanism proposed also by Turner and $\mathrm{Ashby}^{7}$ ), and a lower density will be attained. The trends shown in Fig. 12 are in keeping with these arguments, and it is therefore reasonable to conclude that the synthetic DRI particles are compacted by a yield mechanism. It also follows that pure yielding is the primary mechanism of compaction in the industrial HBI process.

If a relationship between the pressure required to attain a specified compact density and the composition of the DRI could be established, then this information could be utilised as a key process control parameter in the production of HBI. To investigate this possibility further, the compressibility data were replotted against carbon content, as shown in Fig. 13. The limited data set does not allow complete analysis, but it appears that higher pressures are required to attain a given density as the fraction of pearlite in a hypoeutectoid $\mathrm{Fe}-\mathrm{C}$ alloy increases. In fully pearlitic or in hypereutectoid compositions, deformation of the ferrite is severely restricted, as explained above, and significantly higher pressures are required to attain a given density.

The fracture resistance under compression of the compacted samples increases with the density and the carbon content of the compacts, as shown in Figs. 9-11. The influence of density on fracture resistance can be explained in terms of the interaction of particles. Contact areas and interlocking between particles increase with increased applied pressure during compaction. At low densities the contact areas are small, and interlocking between particles is poorly developed. The fracture of a compact in this instance will occur when the applied force overcomes the friction between particles in contact, resulting in interparticle sliding. On the other hand, when a high density has been attained, hard particles should be imbedded in softer particles, thereby increasing the frictional forces between particles and preventing interparticle sliding.

Increasing the carbon content increases the strength of the compact as a whole. Provided that a high enough density has been achieved, the conglomerate of particles behaves almost as if it were a solid, and the hardness of the particles determines the resistance to fracture. Hard particulates such as pearlite or proeutectoid cementite 
will act as fibres in a composite material, inhibiting stress transmission and thereby increasing the fracture resistance of the compacts.

It follows from Fig. 10 that the source of the iron ore has a significant influence on the fracture resistance of the compacts. This behaviour can most likely be attributed to differences in composition, morphology and phase distribution in the different iron ores. This aspect has not been further investigated.

\section{Conclusions}

1. Increasing the carbon content of DRI powders decreases the compressibility of powders produced at $650^{\circ} \mathrm{C}$ but enhances the fracture resistance of the compacts.

2. Because compaction occurs by the plastic flow of individual particles, compressibility is decreased by the presence of hard particles. These hard particles may be iron carbides that are present in DRI of hypereutectoid composition or areas of pearlite in DRI containing less carbon.

3. Hard particulates such as pearlite or proeutectoid cementite will act as fibres in a composite material, inhibiting stress transmission and increasing the fracture resistance of the compacts, provided that sufficient density has been achieved during compaction.

4. Consolidation of the particles occurs solely by a yielding process, and no evidence of creep has been found.

5. The relationship between the amount of pearlite and proeutectoid cementite present in DRI and the compaction pressure required to achieve a given density can be used as an important process control parameter.

\section{Acknowledgements}

The support of BHP-Billiton Technology Centre in Newcastle for this work, conducted at the University of Wollongong, Australia, is gratefully acknowledged. The authors are indebted to Dr T. Honeyands for providing the industrial DRI samples and for many fruitful discussions.

\section{References}

1. A. Hassan and R. Whipp: Iron Steelmaker, 1995, 4, 35-40.

2. A. D. Brent, P. L. J. Mayfield and T. A. Honeyands: Proc. Conf. on 'Alternative routes of iron and steelmaking': ICARISM'99, Perth, Australia, September 1999, AusIMM and CSIRO Minerals, 111-114.

3. R. Hunter: Steel Times, 1995, 3, 105

4. D. Crawford: 'Microstructural analysis of HBI', Private communication, BHP-Billiton Technology Centre, Newcastle, Australia, 2001.

5. E. Arzt , M. F. Ashby and K. E. Easterling: Metall. Trans. A, 1983, 14A, 211-221.

6. A. S. Helle, K. E. Easterling and M. F. Ashby: Acta Metall., 1985, 12, 2163-2174.

7. C. D. Turner and M. F. Ashby: Acta Mater., 1996, 11, 4521-4530.

8. R. L. Hewitt, W. Wallace and M. C. Malherbe: Powder Metall, 1974, 17, 1-12.

9. T. A. Honeyands: 'Effect of carbon and $\mathrm{MgO}$ on briquette strength', Confidential report, BHP-Billiton Technology Centre, Newcastle, Australia, 2000

10. T. A. Honeyands: 'Port Hedland-Orinoco iron briquettability comparison', Technote BHP, Newcastle, NSW, Australia, 2001

11. N. Cárdenas: 'Effect of the carbon content on the FIOR-HBI density and the implications in handling and transportation', MEng thesis. UNEXPO, Puerto Ordaz, Venezuela, 2001.

12. R. J. Dippenaar, W. Melfo, D. Blundell and T. Honeyands: Proc. Australia-Japan 'Iron and steelmaking' Symp., Sydney, Australia, July 2004, University of New South Wales.

13. W. Melfo: 'Early sintering phenomena pertaining to hot briquetted iron', MEng thesis, Wollongong University, Wollongong, Australia, 2002.

14. 'Standard test method for compressibility of metal powders in uniaxial compaction', ASTM standard B331-95, Philadelphia, PA, USA, 1997.

15. M. K. Fahad: J. Mater. Sci., 1996, 31, 3723-3729.

16. A. Rudnick, A. R. Hunter and F. C. Holden: Mater. Res. Stand., 1963, 4, 283-289.

17. H. J. Frost and M. F. Ashby: 'Deformation mechanism maps: plasticity and creep of metals and ceramics', 60; 1982, Oxford, UK, Pergamon Press. 